\title{
1 Future deforestation in the Amazon and 2 consequences for South American climate
}

3 Abigail L.S. Swann ${ }^{\text {a* }}$, Marcos Longo ${ }^{\text {b }}$, Ryan G. Knox ${ }^{\mathrm{c}}$, Eunjee Lee ${ }^{\mathrm{d}}$,

4 Paul R. Moorcroft ${ }^{\mathrm{d}}$

$5 \square$ corresponding author: aswann@u.washington.edu

$6 \quad{ }^{a}$ University of Washington, Department of Atmospheric Sciences, Box

7 351640, Seattle, Washington 98195-1640, USA

$8 \quad$ bmbrapa Satellite Monitoring, Campinas, SP, Brazil

$9 \quad{ }^{\mathrm{c}}$ Lawrence Berkeley National Laboratory, Berkeley, California

$10{ }^{\mathrm{d}}$ Department of Organismic and Evolutionary Biology, Harvard

11 University, Cambridge, Massachusetts 


\section{Abstract}

14 Ongoing agricultural expansion in Amazonia and the surrounding areas of Brazil is expected to continue over the next several decades as global food demand increases. The transition of natural forest and savannah ecosystems to pastureland and agricultural crops is predicted to create warmer and drier atmospheric conditions than the native vegetation. Using a coupled ecosystem regional atmospheric model (EDBRAMS) we investigate the expected impacts of predicted future land use on the climate of South America. The climate response in the model simulations is generally consistent with expectations from previous global modeling simulations with drier conditions resulting from deforestation, however the changes in precipitation are relatively small (on order of a few percent). Local drying is driven primarily by decreases in evapo-transpiration associated with the loss of forest, and concomitant increases in runoff. Significant changes in convectively available potential energy (CAPE) and convective inhibition (CIN) during the transition to the wet season indicate that the decrease in surface latent heat flux is indeed leading to a drier atmosphere, however these changes occur around a mean climatological state that is already very favorable for convection, and thus lead to relatively small changes in precipitation. If, however, these land use changes were to occur under a background state of drier conditions, such as those predicted for the future global climate model experiments, this additional atmospheric drying may be sufficient to decrease precipitation more substantially.

\section{Introduction}

In the broadleaf evergreen forests of Amazonia, the contrasts between the ecological and biophysical functioning of natural forest ecosystems and those of cultivated vegetation is large. Results from numerous studies indicate that the transformation of forested areas to agriculture in the Amazonian region significantly modifies the fluxes of energy, water, and momentum between the land surface and the atmosphere (e.g. Culf et al., 1997). One reason for this is that the transfer of water through vegetation via transpiration contributes large amounts of water to the atmosphere above Amazonia. Trees in Amazonia have been observed to draw water from depths up to $8 \mathrm{~m}$ (Nepstad et al., 1994), and this access to

46 deep water is estimated to increase transpiration in the Amazon by approximately $40 \%$ in the dry season (Lee et al., 2005) because the natural forest vegetation is able to access soil moisture pools unavailable to grasses and agricultural crops (Kim et al., 2012). In addition, pastures are primarily comprised of $\mathrm{C} 4$ grasses with lower rates of transpiration 
for a given rate of photosynthesis compared to tropical trees which utilize $\mathrm{C} 3$

51 photosynthesis. Estimates for the Amazon basin indicate that $25 \%$ to $35 \%$ of precipitation

52 has been previously evaporated or transpired from the surface with local rates up to $50 \%$

53 (Eltahir and Bras, 1994), implying that the vegetation is playing a significant role in

54 convective dynamics and precipitation rates regionally.

55
With changes in land use, the energy budget of the surface is modified. A forested surface is darker, has higher evapo-transpiration rates, and is rougher compared to a surface covered in grass. Changes in these properties lead to a respective change in absorbed solar radiation, latent heat flux, and sensible heat flux, three components of the surface energy budget over land. Although a forested surface absorbs more sunlight causing warmer temperatures, the water fluxes from a mature tropical forest are larger due to a larger leaf area providing more area for transpiration, access to water from a deeper root system, and a higher rate of stomatal conductance per unit leaf area leading to increased latent heat flux. The replacement of forest by agriculture and pasturelands causes a brightening of the land surface, a reduction in leaf area, a reduction in rooting depth, and a reduction in the roughness of the surface (von Randow et al., 2004). The loss of leaf area and deep roots leads to a reduction in evapo-transpiration and, necessarily, an increase in sensible heat flux. These factors all contribute to surface warming and reductions in precipitation.

Significant agricultural and pasture expansion is already occurring in Amazonia, with approximately $11,000 \mathrm{~km}^{2}$ deforested in 2007 alone (Malhi et al., 2008). The annual rate of deforestation in Brazil has decreased since 2005 from 19,000 km2 in 2005 to 4,500 $\mathrm{km} 2$ in 2012, although it increased again in 2013 to 5,900 km2 (INPE 2014).

A large number of studies using global climate models have attempted to quantify changes in precipitation and temperature associated with Amazonian deforestation (Nobre et al., 1991; Dickinson and Kennedy, 1992; Henderson-Sellers et al., 1993; Dirmeyer and Shukla, 1994; Costa and Foley, 2000; Kleidon et al., 2000; Oyama and Nobre, 2004; Nobre and Borma, 2009; Costa and Pires, 2010; Medvigy et al., 2011) as well as numerous studies using regional climate models (Moore et al., 2007; Correia et al., 2008; Ramos da Silva et al., 2008; Lejeune et al., 2014). Several studies (e.g. Costa et al. 2007; Sampaio et al. 2007) investigated the regional impacts of expanded soybean plantations using global scale climate models, and found that reductions in precipitation is larger over soybean plantations than over pasture land. Sampaio et al. (2007) found an apparent threshold that significant reductions in precipitation occur when the area of deforestation exceeds $40 \%$ of the Amazon, although recovery after deforestation may also be hampered by soil nutrient stress (Senna et al., 2009). The magnitude of this deforestation threshold is, however, masked by the uncertainty associated with the ability of General Circulation models to accurately represent the hydroclimate of the Amazon and the ability of global scale ecosystem models to accurately represent the resilience of the vegetation to changes in the hydrologic regimes. In addition to the reduced 
precipitation predicted under conditions of extensive deforestation, 'savannization' is expected in Eastern Amazonia under warming scenarios associated with anthropogenic climate change (Salazar et al., 2007; Senna et al., 2009), and the Amazon basin has been shown to exhibit two stable vegetation states in a model with dynamic vegetation (Oyama and Nobre, 2003). Global dynamic vegetation modeling studies combined with economic assessments and analysis of fire frequency changes during drought have led some to postulate that the Amazon forest may face a 'tipping point' due to land use change in the coming decades, likely perpetuated by changes in fire regime (Nepstad et al., 2008; Nobre and Borma, 2009; Marengo et al., 2011; Davidson et al., 2012; Coe et al., 2013)

The harvested agricultural area of major crops is increasing in Brazil. Major expansions in soybean and sugarcane plantations have been seen since the early 2000's with a $37 \%$ increase in area of soybean harvested in 2009 relative to 2000 and $44 \%$ increase in sugarcane (FAOSTAT, 2010). Deforested areas are typically converted to pastures, comprised largely of C4 grasses (Grace et al., 1998). The expansion of agriculture, soy in particular, may drive deforestation either directly through the clearing of forest to plant crops, or indirectly through the displacement of existing pasture land leading to further clearing for new pasture land (Nepstad et al., 2008; Barona et al., 2010).

The effect of evapo-transpiration on local energy budgets is thought to be the dominant mechanism through which changes in vegetation in tropical forests modify local climates. The conversion of land to soy cultivation has been observed to increase runoff 3 -fold in comparison to forested areas (Hayhoe et al., 2011). A large runoff means that the soy fields are not returning the water delivered to them as precipitation back to the atmosphere through transpiration or canopy evaporation leading to a drying of the atmosphere. Shifts from forest to pasture or agriculture are expected to cause local warming and drying, but as noted above, reductions in evapo-transpiration also impact the water vapor content of the atmosphere. This change in water recycling over land can modify downstream precipitation (Spracklen et al., 2012). In particular, over South America the dominant flow of moisture into the Amazon basin is from oceanic water vapor sources, however the airflow is blocked by the Andes and moisture evaporated from the Amazon basin is transported south (van der Ent et al., 2010; Arraut et al., 2012). Nearly $80 \%$ of precipitation that falls over agricultural growing regions in southern Brazil originates as evaporation from the land surface (see Fig. 3 from van der Ent et al., 2010). This suggests that changes in land use in a region atmospherically upstream can influence precipitation in a region atmospherically downstream, even if the two locations are geographically separated. Rain-fed agriculture is vulnerable to changes in precipitation. Decreases in precipitation downstream from a deforested Amazon forest could hamper agricultural productivity of Brazil, an economic sector comprising approximately 16\% of Brazil's Gross Domestic Product (CEAEA 2014). Current distributions of rain-fed agriculture in South America show that soybeans are grown in largest numbers closer to the Amazon forest (such as in Mato Grosso state) while large areas of sugar and maize production occur farther south (Portmann et al., 2010). The 
majority of sugarcane harvested in Brazil is grown as rain-fed agriculture: in 2000 less than $6 \%$ of sugarcane grown in Sao Paulo State, the Brazilian state with the highest sugarcane production, was irrigated (Portmann et al., 2010). Small-plot agriculture growing locally within regions dominated by forest could also be impacted by deforestation, with drier conditions leading to a reduction in crop yield. This drop in agricultural productivity within the forest could potentially create a positive feedback by driving greater expansion of agricultural area through additional deforestation (Lapola et al., 2010) although agricultural expansion and deforestation have become increasingly decoupled in recent years (Lapola et al., 2014).

The objective of this study was to quantify the impact of the projected shifts towards increased agriculture and pasture within the Amazon on climate of the Amazon and surrounding regions. To do so, we employ a coupled ecosystem-regional climate model with explicit long-term vegetation dynamics in tropical forests. This study is unique compared with other recent work looking and the impacts of future climate and land use change on the Amazon (Zhang et al., 2015) in that in addition to representing ecosystem dynamics we consider the coupled land-atmosphere system and allow changes in land use to feed back on hydrologic cycling in the atmosphere. It is essential that these experiments be performed in coupled model context in order to evaluate the influence of land surface changes on the atmosphere and resulting climate. We focus here on the biophysical interactions between the land surface and climate following deforestation rather than changes in carbon cycling (i.e. Aguiar et al., 2012; Aragão et al., 2014).

\section{Methods}

\subsection{Model Overview}

In this study we use a coupled biosphere-atmosphere model to investigate the stability of the hydrologic cycle within Brazil, from both an agricultural and ecological perspective, under scenarios of increasing deforestation and agricultural conversion. Specifically, we use the ED2 biosphere model (Medvigy et al., 2009) coupled with the Brazilian developments on the Regional Atmospheric Modeling System (BRAMS) regional atmospheric model (Knox et al., 2015).

The ED2 model is a land surface model with an ecosystem simulator that tracks the changes in the size and composition of the plant canopy and the horizontal heterogeneity of the land-surface that they inhabit. Vegetation dynamics of growth, mortality, and seasonal phenology are all represented as a function of plant type and size. Mortality of an individual occurs due to tree-fall as well as carbon starvation. Recruitment occurs as a function of carbon allocation to seeds. Within each resource environment, ED2 allows individuals of multiple types to compete directly for resources (light and water) and grow using these resources over time. Plant types are represented by 4 plant functional types (PFT), 1) early successional trees characterized as fast growing, low wood density, light 
and water needy, 2) mid-successional trees, 3) late successional trees characterized as slow growing, shade tolerant, high wood density, and 4) C4 grasses.

171 In contrast to traditional 'big-leaf' ecosystem models that represent ecosystems in a 172 highly aggregated manner, the ED2 biosphere model is capable of a more realistic 173 representation of both natural vegetation dynamics and the dynamics heterogeneous 174 landscapes containing mixtures of natural and agricultural areas and secondary forests 175 (Albani et al., 2006; Moorcroft, 2006). This is achieved by tracking the dynamic finescale horizontal spatial variation in the distribution of resource environments within each grid cell caused by natural and human disturbance events. Specifically, the model tracks the evolving landscape age structure, where the age of a given place is defined as time since it last experienced a disturbance event of a given type. These disturbance events include tree-fall and fire disturbances and the perturbations associated with land-use transitions. In particular, the ED2 model has been shown to more accurately simulate the regional spatial variation in observed patterns of above ground biomass across the Amazon something that aggregated land surface models are unable to capture (Levine et al., personal communication; Zhang et al., 2015). For further description of the ED2 model please see Moorcroft et al. (2001) and Medvigy et al. (2009).

Crops and pasture are both treated as C4 grasses in the model. The physical influence of plant cover properties on the atmosphere in the tropics is dominated by the control of surface latent heat fluxes, with secondary effects from surface albedo (Bonan 2008). The leaf area of any plant type in the model is calculated as a function of the specific leaf area and the mass of carbon in the leaf pool which dynamically changes over time with modeled photosynthetic rates and loss to leaf turnover. The predicted leaf area index (LAI) for C4 grasses \& forbs (which includes crops and pasture) following deforestation are around 2 to $2.5 \mathrm{~m}^{2} / \mathrm{m}^{2}$ (Fig. S2) values that compare well against measurements in Amazon pastures of $2.5 \mathrm{~m}^{2} / \mathrm{m}^{2}$ (Zanchi et al., 2009). The albedo of a flat leaf is set as a model parameter, as is the leaf angle distribution. The resulting actual surface albedo is dynamically calculated by the model as a function of the canopy leaf area profile and leaf angle distribution Surface latent heat fluxes are calculated as a function of the dynamically varying stomatal conductance, leaf energy balance, and vapor pressure deficit of the canopy air space. The albedo of a flat leaf is set as a model parameter, as is the leaf angle distribution. The resulting actual surface albedo is dynamically calculated by the model as a function of leaf area and leaf angle distribution.

The atmospheric component of our simulation framework is the Brazilian developments on the Regional Atmospheric Modeling System (BRAMS), a multipurpose, regional atmospheric model designed to simulate atmospheric circulations over Brazil and surrounding areas (Freitas et al., 2007; Longo et al., 2013). The ED2 and BRAMS models have already been successfully coupled as part of an existing project looking at biosphere-atmosphere feedbacks in the Amazon system and evaluated against observations in Knox et al. (2015) and Longo (2013). Regional atmospheric models 
represent all of the local atmospheric physics including circulation, parameterized convection, precipitation, and radiation. Simulations with regional atmospheric models require information on advection of mass and water to be provided at the boundaries of the calculation domain. We do this by providing the information from an atmospheric model run at a coarser resolution. The benefit is that a smaller region can be run with higher spatial resolution than global-scale simulations. The drawback is that the communication of information at the boundary happens only in one direction, and changes within the domain do not feedback onto the atmosphere outside the simulated region. For this study we use atmospheric boundary conditions for the present day climate from the ERA-Interim reanalysis product which has a spatial resolution of T255 spectral which corresponds to $<80 \mathrm{~km}$ (Dee et al., 2011).

The version of EDBRAMS used here has been evaluated and validated against observations by Knox et al. (2015). We run the coupled model over the domain of $36^{\circ} \mathrm{S}$ to $13^{\circ} \mathrm{N}$ and $82^{\circ} \mathrm{W}$ to $34^{\circ} \mathrm{W}$ (the region shown in Fig. 1) at $64 \mathrm{~km}$ resolution which is a compromise between improved resolution and computational time. Even with this compromise, computational cost and computational time limit the length of our simulations. For this reason we bring the land model into equilibrium in an offline spinup simulation prior to coupling with the atmosphere.

EDBRAMS, particularly the atmospheric component, has some biases that are worth noting for this analysis: The general patterns of precipitation predicted by EDBRAMS are reasonable as compared to Tropical Rainfall Measurement Mission's 3B43 satellite-based observations (Huffman et al., 2007); however, the precipitation predicted by EDBRAMS is too low along the Northeastern coast of South America (Fig. 1C), and the austral winter in Southern Brazil is also too dry (Fig. 1D). Overall, the EDBRAMS model does a reasonably good job representing precipitation compared with other models (e.g. Lejeune et al. 2014). Reflecting the coupled nature of the EDBRAMS model, these biases in precipitation contribute to a low bias in leaf area of $<1$ in areas outside the Amazon basin.

\subsection{Model Simulations}

\subsubsection{Development of Present and Future Land-Use states}

Prior to the coupled model simulations, we conducted offline simulations of the ED2 ecosystem model in order to develop quantitive descriptions of ecosystem state across the region consistent with existing landuse patterns and projections of future land-use patterns. For the spinup simulations only the ED2 model was implemented at 1 degree latitude by 1 degree longitude resolution over the same domain as the coupled model (the region shown in Fig. 1). Starting from a near-bare-ground ecosystem state populated with seedlings of each plant functional type, the model was repeatedly forced with 1969-2008 from the Global Meteorological Forcing Dataset for Land Surface Modeling (which 
combines NCEP/NCAR reanalysis with global observations to correct biases) (Sheffield et al., 2006) until the biomass and composition of the grid-cells across the region came into equilibrium with the climatological forcing. Reaching equilibrium at a given location took anywhere between 30 (in deserts) and 500 (in forests) simulation years depending on the biomass and diversity of the ecosystem. The resulting vegetation after biomass has stabilized is considered the "potential vegetation" state, or that which would exist without 253 anthropogenic land use.

To incorporate the impacts of historical land-use transformation, from this potential ecosystem state, we applied past historical anthropogenic land use disturbances from the Global Land Use Modeling dataset (GLU) (Hurtt et al., 2006). Anthropogenic land use was implemented in each year from the year 1900 to 2000 as specified by the GLU dataset, with all land use occurring between 1700 and 1899 implemented in the first year. Land use change in South America prior to 1900 is small in the GLU dataset, limited to historical rubber plantations around Manaus although Pereira et al. (2010) suggests that low level selective logging has occurred near the mouth of the Amazon and Tocantins rivers since the 17 th century.

263 Land use types designated by the GLU dataset transition between four categories: primary vegetation, secondary vegetation, pasture, and agriculture following the methodology of Albani et al. (2006). Secondary vegetation is defined by the most recent type of disturbance that occurred in a given place and is comprised of the same plant functional types as primary vegetation. Pasture and agriculture are confined to allow only specific plant types, in this case C4 grasses. After simulating the historical period of land use change covered by the GLU, the resulting vegetation cover represents our best estimate of the current vegetation cover across the simulated region and is called the "current land use" state ('Current'). The current land use case is the appropriate comparison with currently observed conditions in the Amazon forest. The leaf area index predicted by the Current simulation is lower across the Amazon basin by about $1 \mathrm{~m}^{2} \mathrm{~m}^{-2}$, and is not well simulated in the Guianas region (north of Pará) compared with the MODIS LAI product. As noted earlier, the low LAI outside of the Amazon basin is due to the dry bias in precipitation represented by BRAMS. For example, spin-up simulations show higher LAI in the former Atlantic Forest and Guiana Shield than coupled simulations due to more precipitation in the driver dataset used for the spinup compared to the rainfall simulated by our coupled model. Similarly, above ground biomass is well simulated across the Amazon basin, but not well simulated in the Guianas. Overall however, ED2 represents the gradient in biomass across a range of water stress found in the region well, especially in comparison with other land models (Zhang et al., 2015).

283 The impacts of future land use on the climate-ecosystem interactions within the region 284 were estimated using the SimAmazonia-1 land-use projections (Fig. 2) which account for proposed road development in the Amazon forest (Soares et al., 2006). SimAmazonia projections are for the Amazon basin only, and so for the remaining areas we assume that 
current rates of land use in the GLU, which are mostly small continue over the remaining decades. Offline simulations using ED2 were run driven by these future land use scenarios from the year 2002 to 2050 . This final vegetation cover in the year 2050 is called the "future land use" state ('Future'). For continuity between the past and the future land use estimates, land use transitions from the GLU dataset were linearly scaled from 1976 to 2002 to match the initial year of the SimAmazonia-1 dataset (Soares et al., 2006) used for future land use projections.

\subsubsection{Coupled Model Simulations}

The effect of land cover changes between present-day ('Current') and 2050 ('Future') on climate-ecosystem interactions within the region were then examined by initializing a pair of coupled land-atmosphere simulations using the EDBRAMS model. The coupled land-atmosphere model allows us to examine the impacts of the land-use transitions on the feedbacks between fluxes of energy, water, and momentum on atmospheric circulation and precipitation across the domain. Specifically, the EDBRAMS model was run from 2002 through 2007 using ERA-Interim boundary conditions for the Current and Future land-use states described in the previous section. The simulations have identical atmospheric boundary conditions and differences in climate arise only from changes in vegetation cover due to changes in land use and any resulting feedbacks. Focusing on the present day atmospheric boundary conditions allows us to isolate the effects of land use change independent of changes in climate.

We find that the first year of the simulation shows an adjustment in basin-wide soil moisture (Fig. S4), however this signal decays quickly following that. This is consistent with the spin-up period of 26 months used by Medvigy et al. (2013). To ensure that the initial choice of soil moisture conditions is not a factor in our analysis, we conservatively discarded the first three years of the simulation as spinup; however subsequent analyses show that the results of our analysis are unaffected provided the spinup time is at least one year long. Results reported here are the average of simulation years 2005 to 2007, unless otherwise noted. The simulation period of 6 years, and thus analysis period of 3 years, is constrained by the high computational cost of running the coupled regional ecosystem-atmosphere model. The relatively short length of the simulations is insufficient to average over periods of internal climate variability, which can be of order 50 years (e.g. Deser et al. 2013). However, the pattern of atmospheric and ecosystem response that we find is insensitive to the specific years chosen for analysis, indicating that taking the difference between the two simulations forced by identical meteorology capture a robust signal of the near-term atmospheric response to land cover change in the region.

Resulting climate and ecosystem fields are then analyzed by comparing the Future and Current simulations. Anomalies are calculated as the difference between an experiment and control where a change in variable $\varphi$ is represented by $\Delta \varphi=\varphi_{\text {Future }}-\varphi_{\text {Current. Given }}$ the relatively short length of the simulations, most figures have not been masked for 
significance. Where reported, statistical significance for $\Delta \varphi$ is determined using a Students t-test. For annually reported values we use 2 degrees of freedom for the 3 years of simulation. Significance is reported using a $90 \%$ confidence limit unless otherwise noted.

\section{Results}

\subsection{Changes in land use and ecosystem state}

Imposition of the land-use transitions from the land-use change projection (Fig. 2) results in direct changes to forest cover - primarily deforestation within the Amazon basin, but also some re-growth of forests in the Atlantic states of Southern Brazil (Fig. S2C). Forest re-growth in Southern Brazil occurs in our simulations because little land use change is occurring there at present and the rates of land use conversion from the GLU model from the 1990s were projected into the future. Over the entire domain, $35 \%$ of the area is devoted to agriculture in the year 2050, a value close to, but slightly lower than, the $40 \%$ land use change threshold found by Sampaio et al. (2007) to cause significant change in precipitation (Fig. 2).

The land-use transitions cause closely related reductions in leaf area index and above ground biomass over areas that experience deforestation in Future scenario relative to the Current (Fig. 3). This is expected due to the removal of forest biomass when land transitions from forest to crops or pasture. These changes mirror the changes in the fraction of each gridcell specified as anthropogenic, including both pasture and secondary forest (Fig. S2C). Large reductions in the LAI of both the Late Successional and Early Successional plant functional type classes (Fig. S2A and S2B) occur, while midSuccessional plant functional type shows little change due to its low initial abundance. Coincident with this loss in tree cover is an increase in the LAI of Grasses and Forbs that partially compensates for the loss of tree leaf area (Fig. S2D).

\subsection{Surface Fluxes}

Based on the results of earlier coupled modeling studies, we hypothesized that deforestation and the conversion of forests to grasses and crops would cause local nearsurface climate (i.e. within a single gridcell) to be warmer and drier with these changes being driven by a shift in the balance of the four surface energy budget terms: latent heat, sensible heat, shortwave radiation, and longwave radiation.

Surface latent heat fluxes decrease markedly across the region (Fig. 4A) with deforestation. The surface latent heat flux within a grid-cell is comprised of multiple terms, commonly partitioned into the following sub-components: direct transpiration, evaporation from leaves, and evaporation from the ground. Much of the decrease in total latent heat flux within the Amazon basin from deforestation comes from decreases in 
canopy evaporation (Fig. 4B), since canopy evaporation rates are strongly controlled by leaf area available for interception of rainfall and subsequent re-evaporation. However, transpiration dominates the total change in latent heat flux along the arc of deforestation (Fig. 4C), where land use had already removed tree cover prior to our Current land use state. Transpiration shows less decline farther into the forest because transpiration rates per leaf area increase and compensate for decreases in leaf area associated with deforestation (Fig. 5C) as a loss of total leaf area leads to relatively wetter soil relieving moisture stress on the remaining leaves. Consistent with the release of moisture stress indicated by transpiration rates per leaf area, soil moisture across the basin is higher in the Future case (Fig. S4). The remaining trees in the region are responsible for these increased transpiration rates as grasses in the tropics use the $\mathrm{C} 4$ photosynthetic pathway allowing for less water loss per uptake of carbon leading to reduced rates of transpiration per leaf area. Changes in ground evaporation are small (Fig. 4D). Across each of a number of focus regions, total latent heat flux declines significantly, with the largest declines in Pará (PA) and Rondônia (RO) (Table S1). The net longwave radiation change at the surface looks similar to the latent heat flux pattern, as net longwave is the primary compensation for the changes in latent heat flux (Table S1).

Downwelling shortwave radiation increases in a pattern similar to the imposed land cover change, indicating fewer clouds and more sunlight reaching the surface over deforested regions (Fig. 6A). The spatial pattern of change is also similar to coincident decreases in precipitable water (not shown), however, the changes in this quantity are small. Although the amount of sunlight reaching the surface increases, albedo of the surface goes up with deforestation because the relatively dark forests are converted to relatively bright grass and crops. As a result, the greater downwelling solar radiation is mostly canceled by the higher reflectance of the surface, leading to little change in net absorbed shortwave radiation at the surface (Fig. $6 \mathrm{~B}$ ).

\section{Both sensible heat fluxes and longwave upwelling fluxes are a function of surface} temperature. Canopy temperatures shows little change in the annual mean over most of the Amazon basin, but there are noticeably higher temperatures associated with future land use across the Guiana Shield (north of Pará), in Southern Brazil, and in Bolivia (Fig. 6C). Over the Guiana Shield, this increase is due to a reduction in transpiration, that is balanced in the surface energy budget by temperature driven increases in upward longwave fluxes (Table S1). In Southern Brazil, the increases in temperature are caused by an increase in net short wave radiation driven by a change in surface albedo (Fig. 6B).

397 Changes in Sensible heat fluxes are small throughout the Amazon basin, but show modest 398 increases around the arc of deforestation, and larger increases along the North-Eastern 399 coast of South America (Fig. 6D), some cases being coincident with large increases in 400 canopy temperature. Decreases in sensible heat flux are seen throughout Southern Brazil. 
We examine two metrics of atmospheric stability. Convective Available Potential Energy (CAPE) is a metric of instability in an air column. If CAPE values are low, there is insufficient energy to drive convection. Convective Inhibition (CIN) is a metric of the energy needed for air to overcome atmospheric stability and reach a convective state. Air parcels rising from the surface must have larger amounts of energy available to initiate convection when CIN is high than when CIN is low. High values of CAPE and low values of CIN suggest an unstable atmosphere likely to have convection. Future land use conditions lead to drier atmospheric conditions compared with the present day in our simulations. Surface latent heat fluxes show a large decrease (Fig. 4A), despite increases in transpiration rates per leaf area (Fig. 5C). Associated with this, CAPE decreases (Fig. 7A), and CIN increases (Fig. 7C) both in the annual mean and in the shoulder seasons (Fig. 7 shows the mean for August and September, but the spatial pattern is similar for the annual mean). The patterns of these four changes are consistent spatially, and all go in the direction of a drier atmosphere. Significant changes in CAPE occur during conditions with CAPE values from 2000-3500 J kg-1 and significant changes in CIN occur around mean state values from $50-100 \mathrm{~J} \mathrm{~kg}^{-1}$. Although CAPE is decreasing and CIN is increasing, both consistent with decreases in precipitation, the significant changes are occurring during conditions that are already sufficiently prime for convection (CAPE starts high, CIN starts low).

421 Precipitation changes are, therefore, modest (see Fig 1E-F and Fig. 5A). There are some small changes in precipitation due to land use change with general drying along the Northeastern margin of the Amazon Basin (Fig. 1E-F). A slight increase in precipitation is seen in the region of Goías and a slight decrease in southern Brazil, centered at the southwestern edge of Parańa (see Fig. S1 for geographic information). Decreases in precipitation along the Mato Grosso/Amazonas border show spatial correspondence to changes in shortwave downwelling radiation and imposed deforestation patterns (Fig. 1F and Fig. 6A) with larger absolute changes during the wetter half of the year (Fig. 1E). Although significance of changes in precipitation is difficult to test in the relatively short coupled simulations we present here, we do see spatially coherent correspondence between changes in precipitation and changes in downwelling shortwave radiation at the surface indicating that increases in shortwave radiation follow from decreases in clouds and precipitation (Fig. 1F and Fig. 6A). These spatially co-located increases in downwelling solar radiation and decreases in precipitation are also closely related to the spatial pattern of deforestation (Fig. 2B).

Future land use leads to modest changes in precipitation (Fig. 5A), but large reductions in evapotranspiration (Fig. 5B) such that the difference between them (P-ET) is order of magnitude determined by changes in ET. The gain of water on land, from equal rainfall but less water loss to the atmosphere, is compensated for almost entirely by an increase in runoff (Fig. 5D), with a very small change in water storage making up the difference.

\section{Discussion}


442 Future land development in the Amazon basin is projected to convert more primary forest 443 into agricultural land and pasture. We find that the climate response to projected future 444 land use in the Amazon basin is one of atmospheric drying in regions with loss of forest cover. As large areas of land become increasingly anthropogenic, above ground biomass and leaf area index decrease. Albedo in the Amazon basin increases as dark forests are replaced by relatively more reflective grasses, and latent heat fluxes dramatically decrease (Fig. 4A). Downwelling shortwave radiation increases over deforested regions from a decrease in cloud cover which counteracts the increase in albedo.

Mesoscale convective patterns associated with deforestation arise from the contrast in surface energy partitioning between forested and deforested patches and are observable in cloud patterns (Baidya Roy and Avissar, 2002; Wang et al., 2009), with potential increases in rain amounts along the boundary between forest and pasture (Baidya Roy, 2009). High resolution atmospheric simulations $(<1-20 \mathrm{~km})$ have shown that rainfall could increase in some locations with deforestation as changes in land surface properties and energy fluxes initiate mesoscale circulations (Baidya Roy and Avissar, 2002; Baidya Roy et al., 2003; Baidya Roy, 2009; Walker et al., 2009; Wang et al., 2009). However, Ramos da Silva et al. (2008) find (using a closely related atmospheric model to the one used here) that while deforestation increases precipitation along the forest-pasture boundary, basin-wide precipitation decreases. It has been suggested that regional climate models show less sensitivity in precipitation to changes in forest cover over the Amazon basin compared with global models (Medvigy et al., 2011); however, this is not confirmed by a recent study (Lejeune et al., 2014). The spatial scale of the work presented here is intermediate between the two at $60 \mathrm{~km}$ resolution. While a closely related regional atmospheric model (RAMS) has been shown to simulate mesoscale convections at $20 \mathrm{~km}$ resolution (Ramos da Silva et al., 2008) even while still parameterizing convection, our simulations may not resolve them directly. We find in our simulations there are modest changes in precipitation generally, with slight decreases in precipitation at land use-boundaries.

Changes in precipitation due to deforestation have been hypothesized to occur during the beginning and end of the wet season ( $\mathrm{Fu}$ and $\mathrm{Li}, 2004)$. During the peak of the rainy season, large-scale advection of moisture is large enough to sustain precipitation without assistance from local water sources. In the shoulder seasons, at the start and end of the wet season, the local evapo-transpiration fluxes play a larger role, with more precipitation expected with greater forest cover (and associated high rates of transpiration) (Lee and Boyce, 2010; Lee et al., 2011). This could lead to increases in the length of the dry season over the Amazon (Fu et al., 2013). In our simulations we show a reduction in surface latent heat flux and a decrease in cloud cover over deforested areas, both consistent with a drier atmosphere although decreases in precipitation are moderate.

Why then does a drier atmosphere produce little or no change in amount of precipitation? We hypothesize that although the drying is significant in a statistical sense, the decreases 
in CAPE come during conditions where there was already more than enough CAPE to initiate convection (Fig. 7B), even during the shoulder seasons (see schematic in Fig. 8). Similarly, although CIN increases, which should suppress convection and rainfall, it is increasing from very low mean state values, such that the final CIN is still too low to suppress convection (Fig. 7D). Yin et al. (2014) find that CIN and CAPE during the onset of the wet season in the Amazon vary from $750-890 \mathrm{~J} \mathrm{~kg}^{-1}$ for CAPE and $50-60 \mathrm{~J} \mathrm{~kg}^{-1}$ for $\mathrm{CIN}$ between years with very early onset and very late onset. In our simulations, CAPE is changing significantly only when the mean state value falls from $2000-3500 \mathrm{~J} \mathrm{~kg}^{-1}$, suggesting that our modeled atmosphere is more primed for convection than the real atmosphere during the onset season. The significant simulated changes in CIN are in the $50-100 \mathrm{~J} \mathrm{~kg}^{-1}$ range mostly larger than the CIN values found by Yin et al. (2014), suggesting that our modeled atmosphere does have slightly more inhibition than the real atmosphere. Thus, despite very large changes in surface latent heat flux, the changes in atmospheric stability are happening during consistently unstable atmospheric conditions (particularly with respect to CAPE), and so have little effect on precipitation. Locations with a drying atmosphere due to deforestation do not see a significant difference in precipitation because the system is already unstable and therefore insensitive to a change in CAPE.

Prior studies using global climate models show larger reductions in precipitation with deforestation compared with the results presented here (e.g. Sampaio et al., 2007; Nobre and Borma, 2009; Costa and Pires, 2010). It is likely that the atmospheric stability over the Amazon, particularly in the shoulder seasons, was closer to the threshold for convection occurring due to lower CAPE, higher CIN, or both compared the simulations conducted here. Differences in background state of atmospheric stability are likely driven by differences in how convection is parameterized and microphysical rain is calculated. While in general global-scale GCMs struggle to accurately reproduce precipitation over the Amazon region (e.g. Malhi et al., 2009), at present it is unclear whether the higher resolution regional simulations conducted here are closer to representing the true state of the atmosphere over the Amazon.

\section{Conclusions and Implications}

513 Here we have tested the early response of the coupled land-atmosphere system in South

514 America to deforestation across the Amazon basin using a regional coupled ecosystem 515 dynamics-atmosphere model. Our analysis indicates that decreases in canopy leaf area 516 arising from deforestation lead to a reduction in latent heat flux and an associated 517 increase in runoff and decrease in moisture stress indicated by an increase in transpiration 518 per leaf area. The decrease in latent heat flux leads to a reduction in CAPE, and an increase in CIN; however, these both occur at mean state values too high (in the case of

520 CAPE) or too low (in the case of CIN) to significantly reduce convection and 
521 precipitation (Fig. 8). These findings are consistent in their sign with prior work, but the 522 overall magnitude of precipitation change is relatively small in our simulations, despite

523 significant changes in convective instability and available energy.

524 Future climate change is expected to bring drier conditions to the Amazon basin (Malhi et 525 al., 2008, 2009; Joetzjer et al., 2013). If, as we expect, deforestation occurs superimposed 526 on a background state of drying, we postulate that drying feedback associated with the 527 loss of transpiring trees could accelerate the movement across a convective threshold to 528 more severe reductions in rainfall.

529 This work highlights the uncertainty associated with the coupled response of the ecoclimate, or coupled ecosystem-climate system, to changes in the surface energy balance. Unlike previous work (e.g. Sampaio et al., 2007; Nobre and Borma, 2009; Costa and Pires, 2010; Medvigy et al., 2011), we find that despite large reductions in latent heat flux associated with deforestation we do not find significant corresponding reductions in precipitation. This suggests that uncertainty remains in our basic understanding of atmospheric response to surface forcing over the Amazon. Specifically, how do surface fluxes of water and energy modify convection locally, and how does this compare with large-scale environmental drivers of convection? How will these interactions be modified by changes to climate from increases in greenhouse gasses? Further research is needed to elucidate how coupled land-atmosphere systems respond to perturbations to the surface energy balance, particularly from changes in forest cover.

We acknowledge National Science Foundation Awards AGS-1321745 and EF-1340649 to the University of Washington, as well as National Science Foundatiaon Award ATM0449793 and National Aeronautics and Space Administration Grant NNG06GD63G to the Massachusetts Institute of Technology. This work was partially conducted while A.L.S.S. and E.L. were Giorgio Ruffolo Fellows in the Sustainability Science Program at Harvard University, for which support from Italy's Ministry for Environment, Land and Sea is gratefully acknowledged. M.L. was supported by Conselho Nacional de Desenvolvimento Científico e Tecnológico (CNPq). Britaldo Soares Filho provided the SimAmazonia scenarios. We would like to thank an anonymous reviewer for their constructive comments. Jung-Eun Lee, Benjamin Lintner, and Daehyun Kim provided

\section{References}

554 Aguiar, A. P. D., et al., Modeling the spatial and temporal heterogeneity of deforestation555 driven carbon emissions: the INPE-em framework applied to the brazilian amazon, 556 Global Change Biology, 18(11), 3346-3366, doi:10.1111/j.1365-2486.2012.02782.x, 5572012. 
558 Albani, M., D. Medvigy, G. C. Hurtt, and P. R. Moorcroft, The contributions of land-use 559 change, $\mathrm{CO} 2$ fertilization, and climate variability to the eastern us carbon sink, Global 560 Change Biology, 12(12), 2370-2390, doi:DOI 10.1111/j.1365-2486.2006.01254.x, 2006.

561 Aragão, L. E. O. C., B. Poulter, J. B. Barlow, L. O. Anderson, Y. Malhi, S. Saatchi, O. L. 562 Phillips, and E. Gloor, Environmental change and the carbon balance of Amazonian 563 forests, Biological Reviews, 89(4), 913-931, doi:10.1111/brv.12088, 2014.

564 Arraut, J. M., C. Nobre, H. M. J. Barbosa, G. Obregon, and J. Marengo, Aerial rivers and 565 lakes: Looking at large-scale moisture transport and its relation to Amazonia and to 566 subtropical rainfall in south america, Journal of Climate, 25(2), 543-556, doi:DOI 567 10.1175/2011JCLI4189.1, 2012.

568 Baidya Roy, S., Mesoscale vegetation-atmosphere feedbacks in Amazonia, Journal of 569 Geophysical Research: Atmospheres (1984-2012), 114(D20), 2009.

570 Baidya Roy, S., and R. Avissar, Impact of land use/land cover change on regional 571 hydrometeorology in Amazonia, Journal of Geophysical Research: Atmospheres (1984572 2012), 107(D20), LBA-4, 2002.

573 Baidya Roy, S., C. P. Weaver, D. S. Nolan, and R. Avissar, A preferred scale for 574 landscape forced mesoscale circulations?, Journal of Geophysical Research: Atmospheres 575 (1984-2012), 108(D22), 2003.

576 Barona, E., N. Ramankutty, G. Hyman, and O. T. Coomes, The role of pasture and 577 soybean in de- forestation of the Brazilian Amazon, Environmental Research Letters, 578 5(2), doi:DOI 10.1088/1748- 9326/5/2/024002, 2010.

579 Bonan, G. B., Forests and climate change: Forcings, feedbacks, and the climate benefits 580 of forests, Science, 320(5882), 1444-1449, doi:DOI 10.1126/science.1155121, 2008.

581 CEAEA - Centro de Estudos Avancados em Economia Aplicada, Brazil agribusiness 582 GDP 1994-2011, 583 http://www.cepea.esalq.usp.br/english/gdp/BR_Agrib_GDP_Cepea_1994_2011.xls, 5842014.

585 Coe, M. T., et al., Deforestation and climate feedbacks threaten the ecological integrity of 586 south-southeastern Amazonia, Philosophical Transactions of the Royal Society B:

587 Biological Sciences, 368(1619), doi:10.1098/rstb.2012.0155, 2013.

588 Correia, F. W. S., R. C. S. Alvalá, and A. O. Manzi, Modeling the impacts of land cover 589 change in Amazonia: a regional climate model (RCM) simulation study, Theoretical and 590 Applied Climatology, 93(3- 4), 225-244, doi:10.1007/s00704-007-0335-z, 2008.

591 Costa, M., and J. Foley, Combined effects of deforestation and doubled atmospheric $\mathrm{CO}_{2}$ 
592 concentrations on the climate of Amazonia, Journal of Climate, 13(1), 18-34, 2000.

593 Costa, M., and G. Pires, Effects of Amazon and central Brazil deforestation scenarios on 594 the duration of the dry season in the arc of deforestation, International Journal of 595 Climatology, 30(13), 1970-1979, 2010.

596 Costa, M. H., S. N. M. Yanagi, P. J. O. P. Souza, A. Ribeiro, and E. J. P. Rocha, Climate 597 change in Amazonia caused by soybean cropland expansion, as compared to caused by 598 pastureland expansion., Geophysical Research Letters, 34(7), 599 doi:10.1029/2007GL029271, 2007.

600 Culf, A., G. Fisch, Y. Malhi, and C. Nobre, The influence of the atmospheric boundary 601 layer on carbon dioxide concentrations over a tropical forest, Agricultural and forest 602 meteorology, 85 (3), 149-158, 1997.

603 Davidson, E. A., et al., The Amazon basin in transition, Nature, 481 (7381), 321-328, 604 doi:DOI 10.1038/nature10717, 2012.

605 INPE - Instituto Nacional de Pesquisas Espaciais Projeto Prodes, Projeto Prodes:

606 Monitoramento da Floresta Amazônica brasileira por satélite,

607 http://www.obt.inpe.br/prodes/index.php, 2014.

608 Dee, D. P., et al., The ERA-interim reanalysis: configuration and performance of the data 609 assimilation system, Quarterly Journal of the Royal Meteorological Society, 137(656), 610 553-597, doi:10.1002/qj.828, 2011.

611 Deser, C., A. S. Phillips, M. A. Alexander, and B. V. Smoliak, Projecting North 612 American climate over the next 50 years: Uncertainty due to internal variability, Journal 613 of Climate, 27(6), 2271-2296, doi: 10.1175/JCLI-D-13-00451.1, 2013.

614 Dickinson, R. E., and P. Kennedy, Impacts on regional climate of Amazon deforestation, 615 Geophysical Research Letters, 19(19), 1947-1950, 1992.

616 Dirmeyer, P. A., and J. Shukla, Albedo as a modulator of climate response to tropical 617 deforestation, Journal of Geophysical Research-Atmospheres, 99(D10), 20,863-20,877, 6181994.

619 Eltahir, E., and R. Bras, Precipitation recycling in the Amazon basin, Quarterly Journal of 620 the Royal Meteorological Society, 120(518), 861-880, 1994.

621 FAOSTAT, Rome: Food and agricultural organization, united nations, 622 http://faostat.fao.org, 2010.

623 Freitas, S. R., et al., Including the sub-grid scale plume rise of vegetation fires in low 624 resolution atmospheric transport models, Atmospheric Chemistry and Physics, 7(13), 
$626 \mathrm{Fu}, \mathrm{R}$., and $\mathrm{W}$. Li, The influence of the land surface on the transition from dry to wet 627 season in Amazonia, Theoretical and Applied Climatology, 78(1-3), 97-110, 2004.

$628 \mathrm{Fu}, \mathrm{R}$., et al., Increased dry-season length over southern Amazonia in recent decades and 629 its implication for future climate projection, Proceedings of the National Academy of 630 Sciences, doi:10.1073/pnas.1302584110, 2013.

631 Grace, J., J. Lloyd, A. C. Miranda, H. Miranda, and J. H. C. Gash, Fluxes of carbon 632 dioxide and water vapour over a $\mathrm{C} 4$ pasture in southwestern Amazonia (Brazil), 633 Functional Plant Biology, 25(5), 519-530, 1998.

634 Hayhoe, S., C. Neill, S. Porder, R. McHorney, P. Lefebvre, M. Coe, H. Elsenbeer, and A. 635 Krusche, Conversion to soy on the Amazonian agricultural frontier increases streamflow

637 Henderson-Sellers, A., R. E. Dickinson, T. B. Durbidge, P. J. Kennedy, K. Mcguffie, and 638 A. J. Pitman, Tropical deforestation - modeling local-scale to regional-scale climate 639 change, Journal of Geophysical Research-Atmospheres, 98(D4), 7289-7315, 1993.

640 Huffman, G. J., D. T. Bolvin, E. J. Nelkin, D. B. Wolff, R. F. Adler, G. Gu, Y. Hong, K. 641 P. Bowman, and E. F. Stocker, The TRMM multisatellite precipitation analysis (TMPA): 642 Quasi-global, multiyear, combined- sensor precipitation estimates at fine scales, Journal 643 of Hydrometeorology, 8(1), 38-55, 2007.

644 Hurtt, G. C., S. Frolking, M. G. Fearon, B. Moore, E. Shevliakova, S. Malyshev, S. W. 645 Pacala, and R. A. Houghton, The underpinnings of land-use history: three centuries of 646 global gridded land-use transitions, wood-harvest activity, and resulting secondary lands, 647 Global Change Biology, 12(7), 1208-1229, doi:DOI10.1111/j.1365-2486.2006.01150.x, 6482006.

649 Joetzjer, E., H. Douville, C. Delire, and P. Ciais, Present-day and future Amazonian 650 precipitation in global climate models: CMIP5 versus CMIP3, Climate Dynamics, 41(11651 12), 2921-2936, doi:10.1007/s00382-012- 1644-1, 2013.

652 Kim, Y., R. G. Knox, M. Longo, D. Medvigy, L. R. Hutyra, E. H. Pyle, S. C. Wofsy, R. 653 L. Bras, and P. R. Moorcroft, Seasonal carbon dynamics and water fluxes in an Amazon 654 rainforest, Global Change Biology, 18(4), 1322-1334, 2012.

655 Kleidon, A., K. Fraedrich, and M. Heimann, A green planet versus a desert world: 656 Estimating the maximum effect of vegetation on the land surface climate, Climatic 657 Change, 44 (4), 471-493, 2000.

658 Knox, R. G., M. Longo, A. L. S. Swann, K. Zhang, N. M. Levine, P. R. Moorcroft, and 
R. L. Bras, Hydrometeorological effects of historical land-conversion in an ecosystematmosphere model of northern South America, Hydrology and Earth System Sciences, 19 (1), 241-273, doi:10.5194/hess-19-241-2015, 2015.

662 Lapola, D. M., R. Schaldach, J. Alcamo, A. Bondeau, S. Msangi, J. A. Priess, R. Silvestrini, and B. S. Soares-Filho, Impacts of climate change and the end of

664 deforestation on land use in the Brazilian legal Amazon, Earth Interactions, 15(16), 1-29, 665 doi:10.1175/2010EI333.1, 2010.

Lapola, D. M., et al., Pervasive transition of the Brazilian land-use system, Nature Climate Change, 4(1), 27-35, 2014.

Lee, J.-E., and K. Boyce, Impact of the hydraulic capacity of plants on water and carbon fluxes in tropical South America, Journal of Geophysical Research-Atmospheres, 115, D23,123, doi:DOI 10.1029/2010JD014568, 2010.

671 Lee, J. E., R. S. Oliveira, T. E. Dawson, and I. Fung, Root functioning modifies seasonal 672 climate, Proceedings of the National Academy of Sciences of the United States of 673 America, 102(49), 17,576-17,581, 2005.

674 Lee, J.-E., B. R. Lintner, C. K. Boyce, and P. J. Lawrence, Land use change exacerbates 675 tropical South American drought by sea surface temperature variability, Geophysical 676 Research Letters, 38, L19,706, doi: DOI 10.1029/2011GL049066, 2011.

677 Lejeune, Q., E. L. Davin, B. P. Guillod, and S. I. Seneviratne, Influence of Amazonian 678 deforestation on the future evolution of regional surface fluxes, circulation, surface 679 temperature and precipitation, Climate Dynamics, pp. 1-18, doi:10.1007/s00382-014$6802203-8,2014$.

681 Longo, K. M., et al., The chemistry catt-BRAMS model (ccatt-brams 4.5): a regional 682 atmospheric model system for integrated air quality and weather forecasting and research, 683 Geoscientific Model Development, 6(5), 1389-1405, doi:10.5194/gmd-6-1389-2013, 6842013.

685 Longo, M., Amazon forest response to changes in rainfall regime: Results from an 686 individual-based dynamic vegetation model, Ph.D. thesis, Harvard University, 2013. change, deforestation, and the fate of the Amazon, Science, 319(5860), 169-172, doi:10.1126/science.1146961, 2008. McSweeney, and P. Meir, Exploring the likelihood and mechanism of a climate-change692 induced dieback of the Amazon rainforest, Proceedings of the National Academy of 693 Sciences, 106(49), 20,610, 2009. 
Marengo, J., C. Nobre, G. Sampaio, L. Salazar, and L. Borma, Climate change in the amazon basin: Tipping points, changes in extremes, and impacts on natural and human systems, in Tropical Rainforest Responses to Climatic Change, edited by M. Bush, J. Flenley, and W. Gosling, Springer Praxis Books, chap. 9, pp. 259-283, Springer Berlin Heidelberg, doi:10.1007/978-3-642-05383-2_9, 2011.

Medvigy, D., S. C. Wofsy, J. W. Munger, D. Y. Hollinger, and P. R. Moorcroft, Mechanistic scaling of ecosystem function and dynamics in space and time: Ecosystem Demography model version 2, Journal of Geophysical Research-Biogeosciences, 114, doi:DOI 10.1029/2008JG000812, 2009.

704

Medvigy, D., R. L. Walko, and R. Avissar, Effects of deforestation on spatiotemporal distributions of precipitation in South America, Journal of Climate, 24(8), 2147-2163, doi:DOI 10.1175/2010JCLI3882.1, 2011.

Medvigy, D., R. L. Walko, M. J. Otte, and R. Avissar, Simulated changes in northwest US climate in response to Amazon deforestation, Journal of Climate, 26(22), 9115-9136, 2013.

Moorcroft, P., G. Hurtt, and S. Pacala, A method for scaling vegetation dynamics: The Ecosystem Demography model (ED), Ecological Monographs, 71(4), 557-585, 2001.

Moorcroft, P. R., How close are we to a predictive science of the biosphere?, Trends in Ecology and Evolution, 21(7), 400-407, 2006.

Moore, N., E. Arima, R. Walker, and R. Ramos da Silva, Uncertainty and the changing hydroclimatology of the Amazon, Geophysical Research Letters, 34(14), doi:10.1029/2007GL030157, 2007.

Nepstad, D. C., C. M. Stickler, B. S. Filho, and F. Merry, Interactions among amazon land use, forests and climate: prospects for a near-term forest tipping point, Philosophical Transactions of the Royal Society B: Biological Sciences, 363(1498), 1737-1746, doi:10.1098/rstb.2007.0036, 2008.

Nepstad, D. C., et al., The role of deep roots in the hydrological and carbon cycles of Amazonian forests and pastures, Nature, 372(6507), 666-669, 1994.

Nobre, C. A., and L. D. S. Borma, 'tipping points' for the Amazon forest, Current Opinion in Environmental Sustainability, 1(1), 28 - 36, doi:http://dx.doi.org/10.1016/j.cosust.2009.07.003, 2009.

Nobre, C. A., P. J. Sellers, and J. Shukla, Amazonian deforestation and regional climate change, Journal of Climate, 4(10), 957-988, 1991.

727 Oyama, M. D., and C. A. Nobre, A new climate-vegetation equilibrium state for tropical 
South America, Geophysical Research Letters, 30(23), 2003.

729 Oyama, M. D., and C. A. Nobre, Climatic consequences of a large-scale desertification in 730 Northeast Brazil: A GCM simulation study, Journal of Climate, 17(16), 3203-3213, 7312004.

732 Pereira, D., D. Santos, M. Vedoveto, J. Guimarães, and A. Veríssimo, Fatos Florestais da Amazonia 2010, Imazon, Belém, PA, 2010.

734 Portmann, F. T., S. Siebert, and P. Doell, Mirca2000-global monthly irrigated and rainfed crop areas around the year 2000: A new high-resolution data set for agricultural and hydrological modeling, Global Biogeochemical Cycles, 24, GB1011, doi:DOI

Ramos da Silva, R., D. Werth, and R. Avissar, Regional impacts of future land-cover changes on the Amazon basin wet-season climate, Journal of Climate, 21(6), 1153-1170, 2008.

Salazar, L. F., C. A. Nobre, and M. D. Oyama, Climate change consequences on the biome distribution in tropical South America., Geophysical Research Letters, 34(9), doi:10.1029/2007GL029695, 2007.

Sampaio, G., C. Nobre, M. H. Costa, P. Satyamurty, B. S. Soares-Filho, and M. Cardoso, Regional climate change over eastern Amazonia caused by pasture and soybean cropland expansion, Geophysical Research Letters, pp. L17,709-1-7,

747 doi:10.1029/2007GL030612, 2007.

748 Senna, M. C. A., M. H. Costa, and G. F. Pires, Vegetation-atmosphere-soil nutrient feedbacks in the amazon for different deforestation scenarios, Journal of Geophysical Research: Atmospheres, 114(D4), doi:10.1029/2008JD010401, 2009. dataset of meteoro-logical forcings for land surface modeling, Journal of climate, 19(13), 3088-3111, 2006. Soares, B., et al., Modelling conservation in the amazon basin, Nature, 440(7083), 520-523, doi:DOI10.1038/nature04389, 2006. rainfall preceded by air passage over forests, Nature, 489(7415), 282-285, 2012. van der Ent, R. J., H. H. G. Savenije, B. Schaefli, and S. C. Steele-Dunne, Origin and fate of atmospheric moisture over continents, Water Resources Research, 46, W09,525, doi:DOI 759 10.1029/2010WR009127, 2010.

760 von Randow, C., et al., Comparative measurements and seasonal variations in energy and 761 carbon exchange over forest and pasture in south west Amazonia, Theoretical and 762 Applied Climatology, 78 (1-3), 5-26, 2004. 
763 Walker, R., N. J. Moore, E. Arima, S. Perz, C. Simmons, M. Caldas, D. Vergara, and C.

764 Bohrer, Protecting the Amazon with protected areas, Proceedings of the National

765 Academy of Sciences, 106(26), 10,582- 10,586, 2009.

766 Wang, J., F. J. F. Chagnon, E. R. Williams, A. K. Betts, N. O. Renno, L. A. T. Machado, 767 G. Bisht, R. Knox, and R. L. Brase, Impact of deforestation in the Amazon basin on 768 cloud climatology, Proceedings of the National Academy of Sciences of the United States 769 of America, 106(10), 3670-3674, doi:DOI 10.1073/pnas.0810156106, 2009.

770 Yin, L., R. Fu, Y.-F. Zhang, P. A. Arias, D. N. Fernando, W. Li, K. Fernandes, and A. R. 771 Bowerman, What controls the interannual variation of the wet season onsets over the 772 Amazon?, Journal of Geophysical Research: Atmospheres, 119(5), 2314-2328, 773 doi:10.1002/2013JD021349, 2014.

774 Zanchi, F. B., M. J. Waterloo, L. J. G. Aguiar, C. von Randow, B. Kruijt, F. L. Cardoso, 775 and A. O. Manzi, Estimativa do Índice de Área Foliar (IAF) e Biomassa em pastagem no 776 estado de Rondônia, Brasil, Acta Amazonica, 39, 335 - 347, doi:10.1590/S0044-

$77759672009000200012,2009$.

778 Zhang, K., et al., The fate of Amazonian ecosystems over the coming century arising 779 from changes in climate, atmospheric $\mathrm{CO}_{2}$ and land-use, Global Change Biology, 780 doi:10.1111/gcb.12903, 2015. 


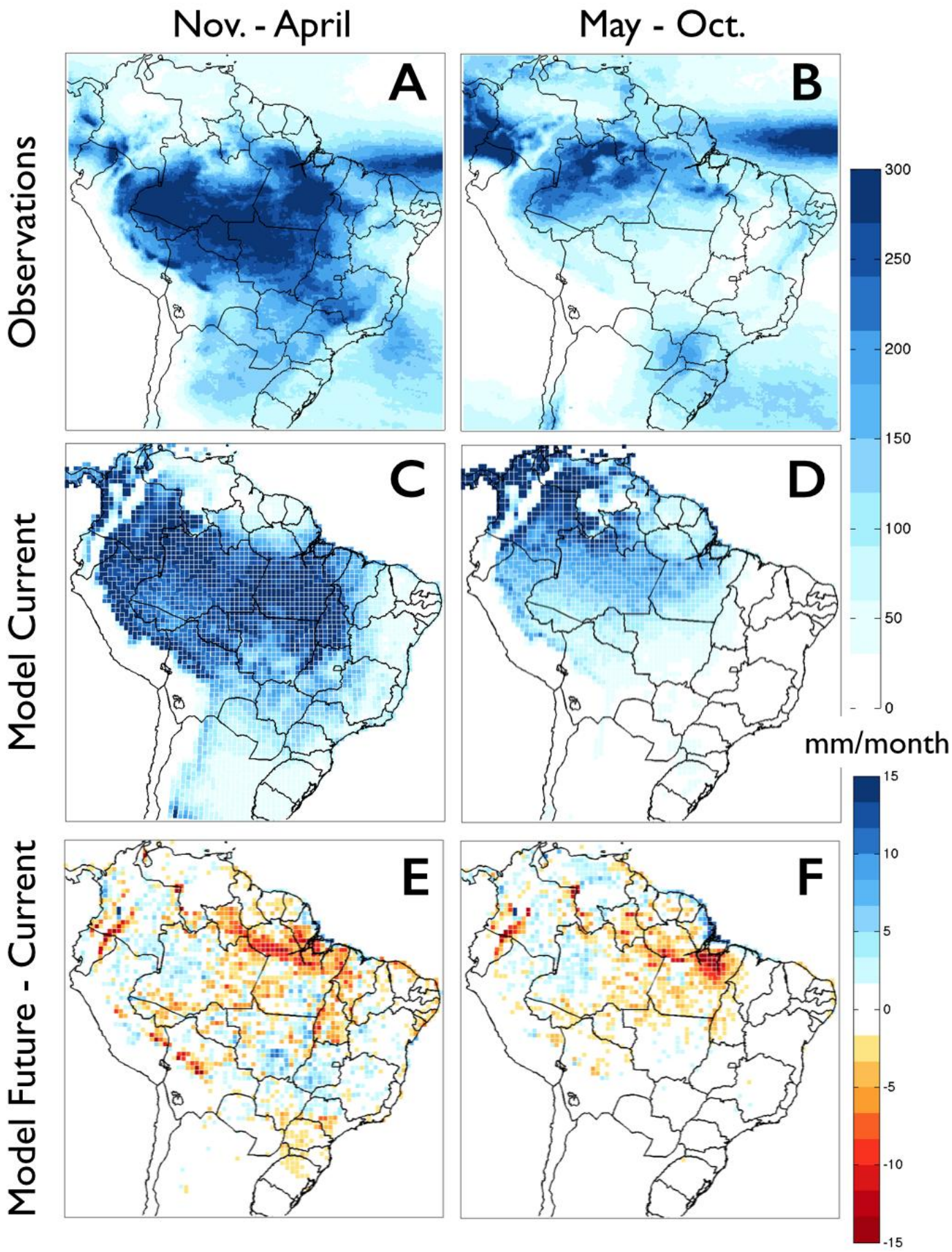

Figure 1: Precipitation (mm month $\left.{ }^{-1}\right)$ : The precipitation rate in $\mathrm{mm} \mathrm{month}^{-1}$ is shown for observations from TRMM (first row, A and B), modeled simulation output for the 'Current' case (second row, $\mathrm{C}$ and D), and the modeled difference due to deforestation (third row, E and F) for the November to April mean (left column, A, C and E) and May to October mean (right column, B, D, F). The upper color bar scale is for panels A through $\mathrm{D}$ and the lower color bar scale is for panels $\mathrm{E}$ and $\mathrm{F}$. 
Current Land Use (2002)

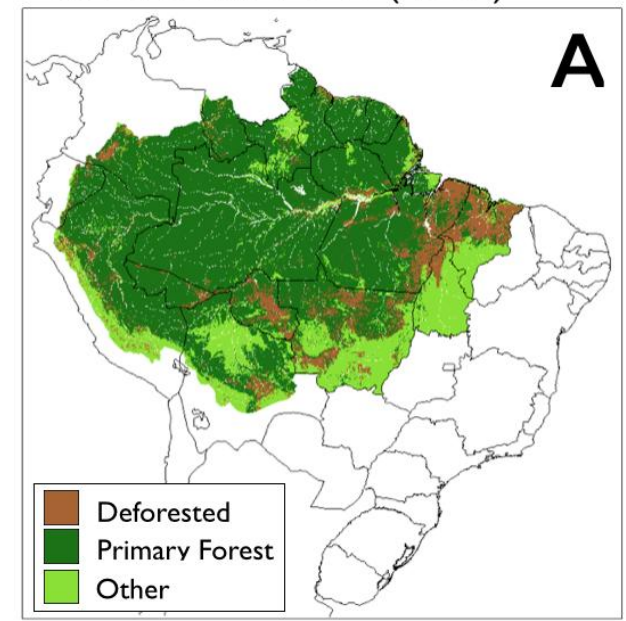

Future Land Use (2050)

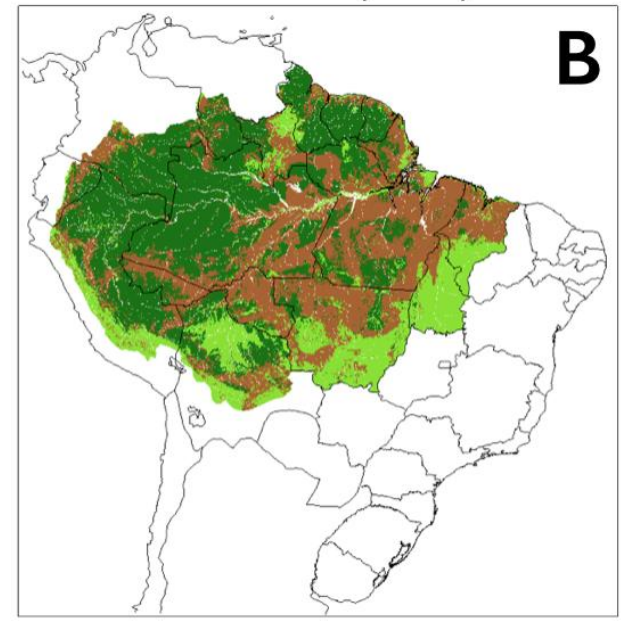

792 Figure 2: SimAmazonia Land Use Projections and map of regions The land use

793 projections of the SimAmazonia scenario is shown for (A) the year 2002, and (B) the 794 year 2050. The different land use categories of primary forest, deforested, and other are 795 identified by dark green pixels, brown pixels, and light green pixels respectively. 

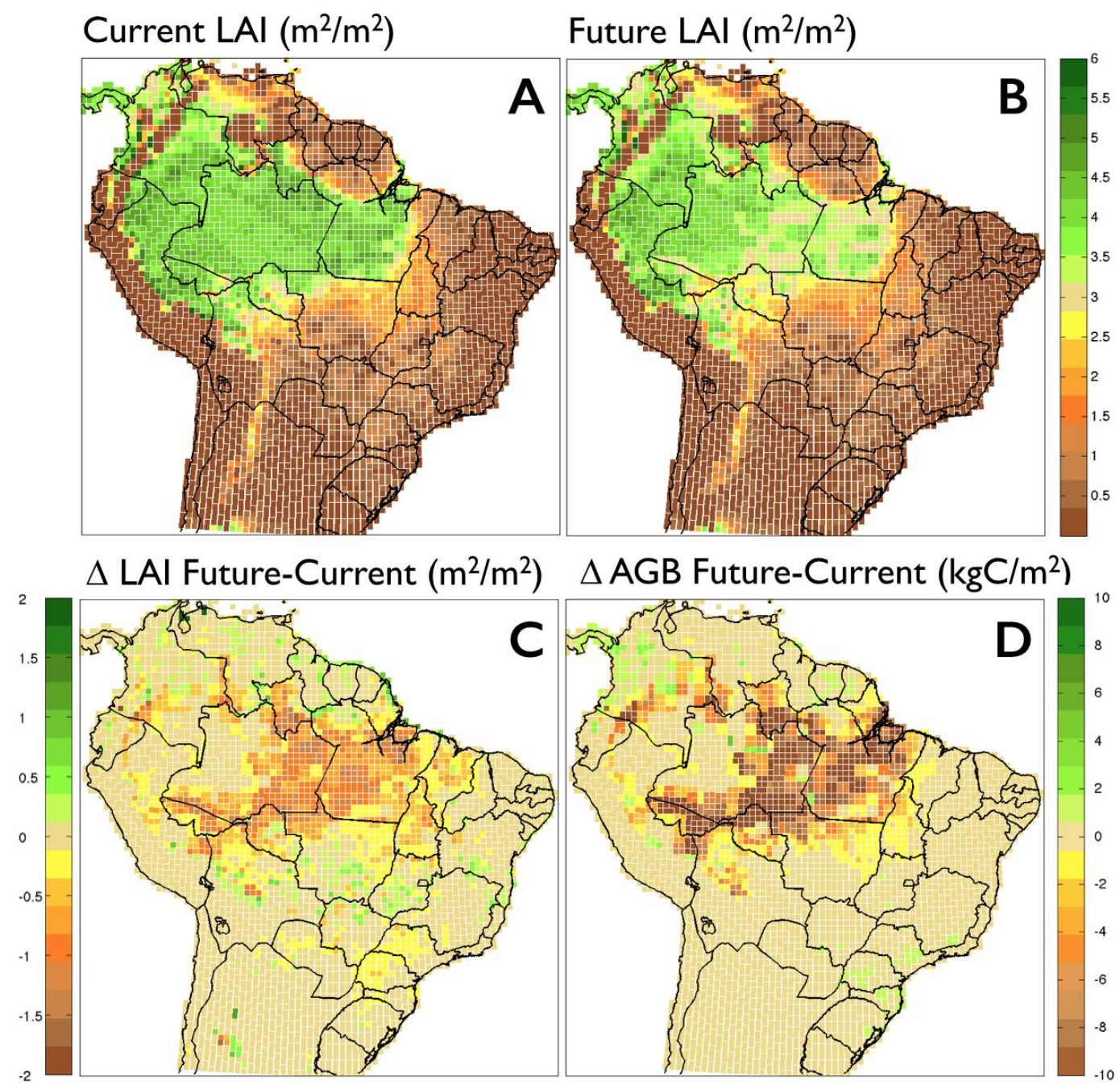

Figure 3: Vegetation Changes: The total leaf area index (LAI) in $\mathrm{m}^{2} \mathrm{~m}^{-2}$ is shown for (A) the Current land use regional simulation, B the Future land use regional simulation, (C) the change in Future LAI compared to Current LAI (Future Current), (D) and the change in above ground biomass (Future Current) in $\mathrm{kgC} \mathrm{m}^{-2}$. The color bar scale for panels A and $\mathrm{B}$ is shown to the right of the top row, and the color bar scale for panels $\mathrm{C}$ and $\mathrm{D}$ are shown to the side of each panel. 
$\Delta$ Total Latent Heat $\left(\mathrm{W} / \mathrm{m}^{2}\right)$

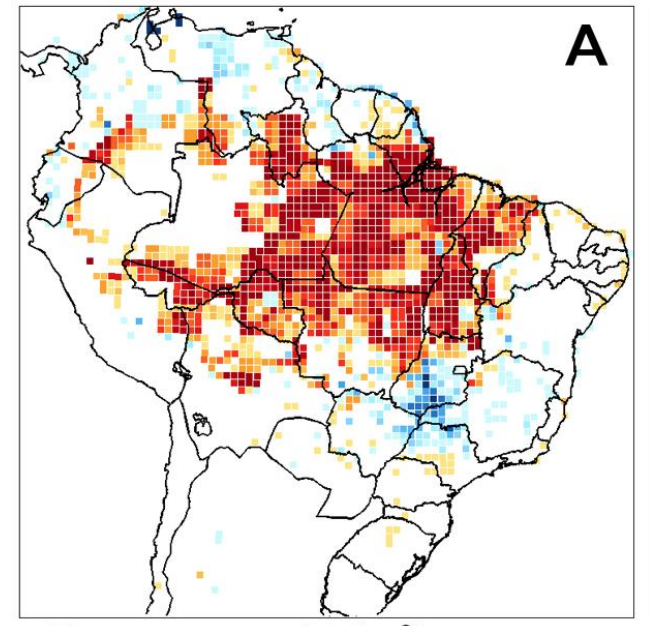

$\Delta$ Transpiration $\left(\mathrm{W} / \mathrm{m}^{2}\right)$

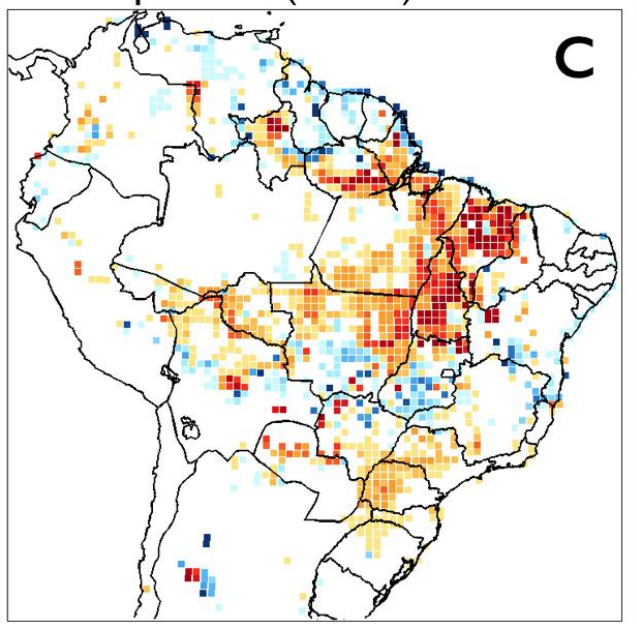

$\Delta$ Canopy Evaporation $\left(\mathrm{W} / \mathrm{m}^{2}\right)$
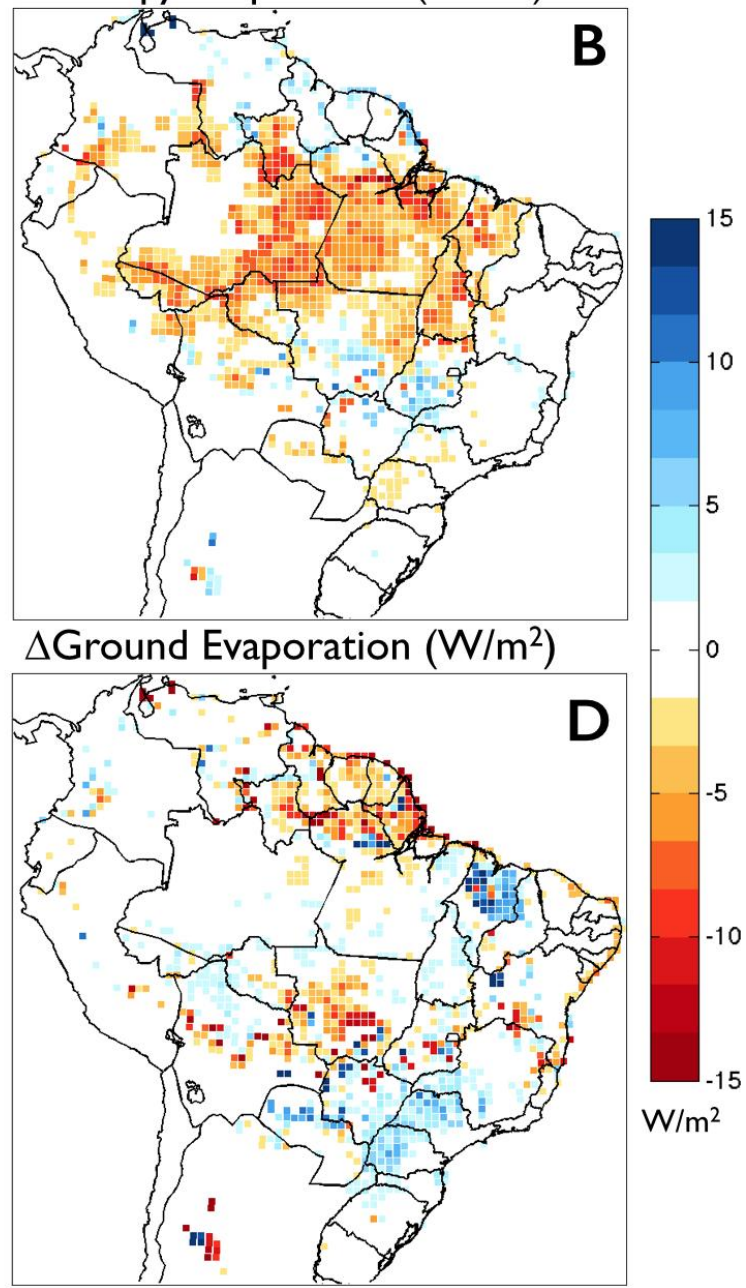

803

804

805

806

807

Figure 4: $\Delta$ Latent Heat Flux components $\left(\mathrm{W} \mathrm{m}^{-2}\right)$ : The change in annual mean (A) total latent heat flux, (B) the contribution from canopy evaporation, (C) the contribution from transpiration, and (D) the contribution from ground evaporation are shown for the Future Current land use cases. 


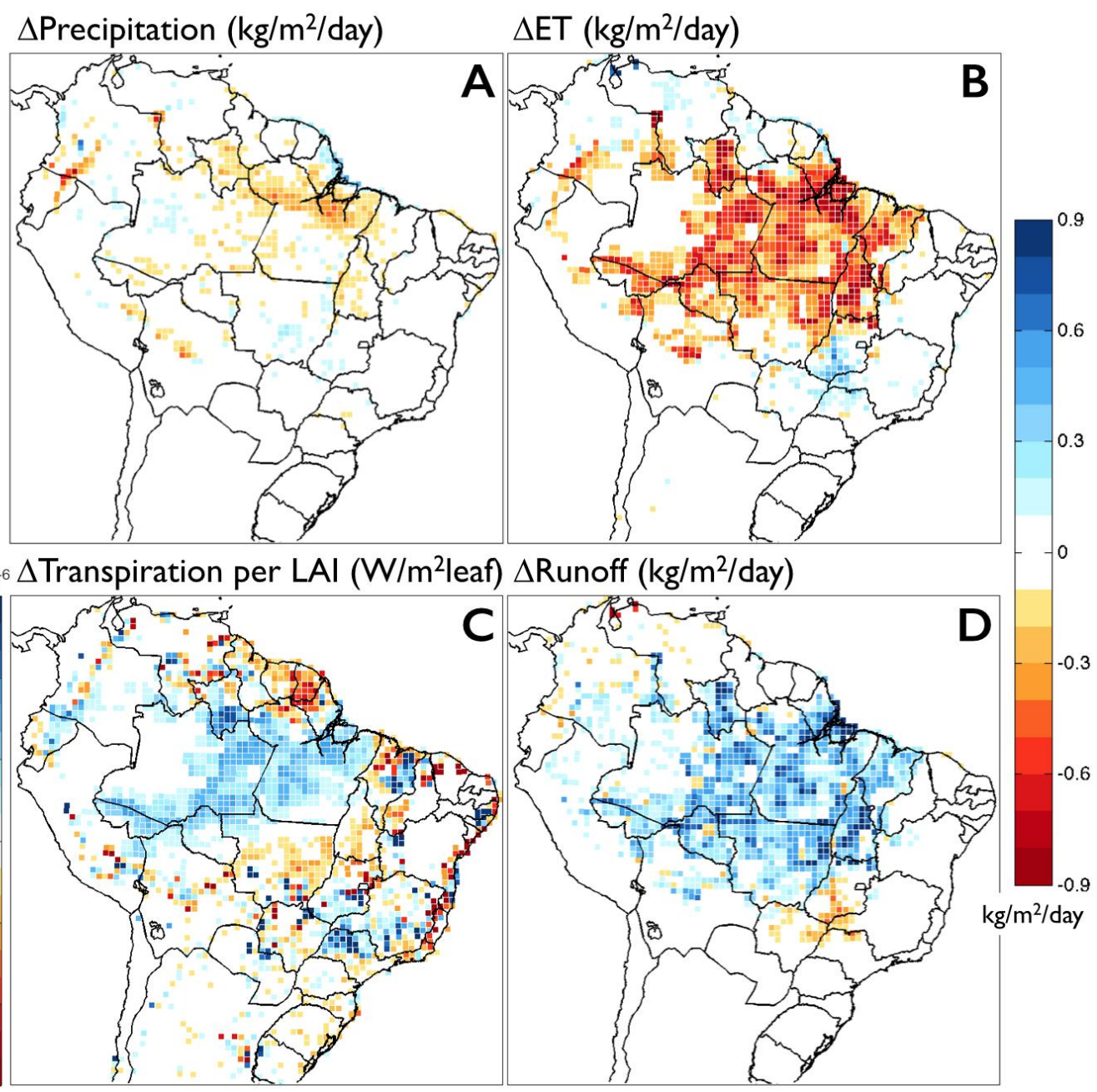

Figure 5: $\Delta$ Water Cycle Components: The change in annual mean (A) precipitation (kg $\left.\mathrm{m}^{-2} \mathrm{day}^{-1}\right),(\mathrm{B})$ evapo-transpiration $\left(\mathrm{kgm}^{-2} \mathrm{day}^{-1}\right),(\mathrm{C})$ transpiration per leaf area index $\left(\mathrm{Wm}^{-2}\right.$ leaf $\left.{ }^{-1}\right)$, and (D) Runoff and Drainage $\left(\mathrm{kg} \mathrm{m}^{-2} \mathrm{day}^{-1}\right)$ are shown for the Future

813 Current land use cases. The color bar scale for panels A, B and D is shown to the right of 814 the figure, and the color bar scale for panel $\mathrm{C}$ is shown to the left of the panel. 


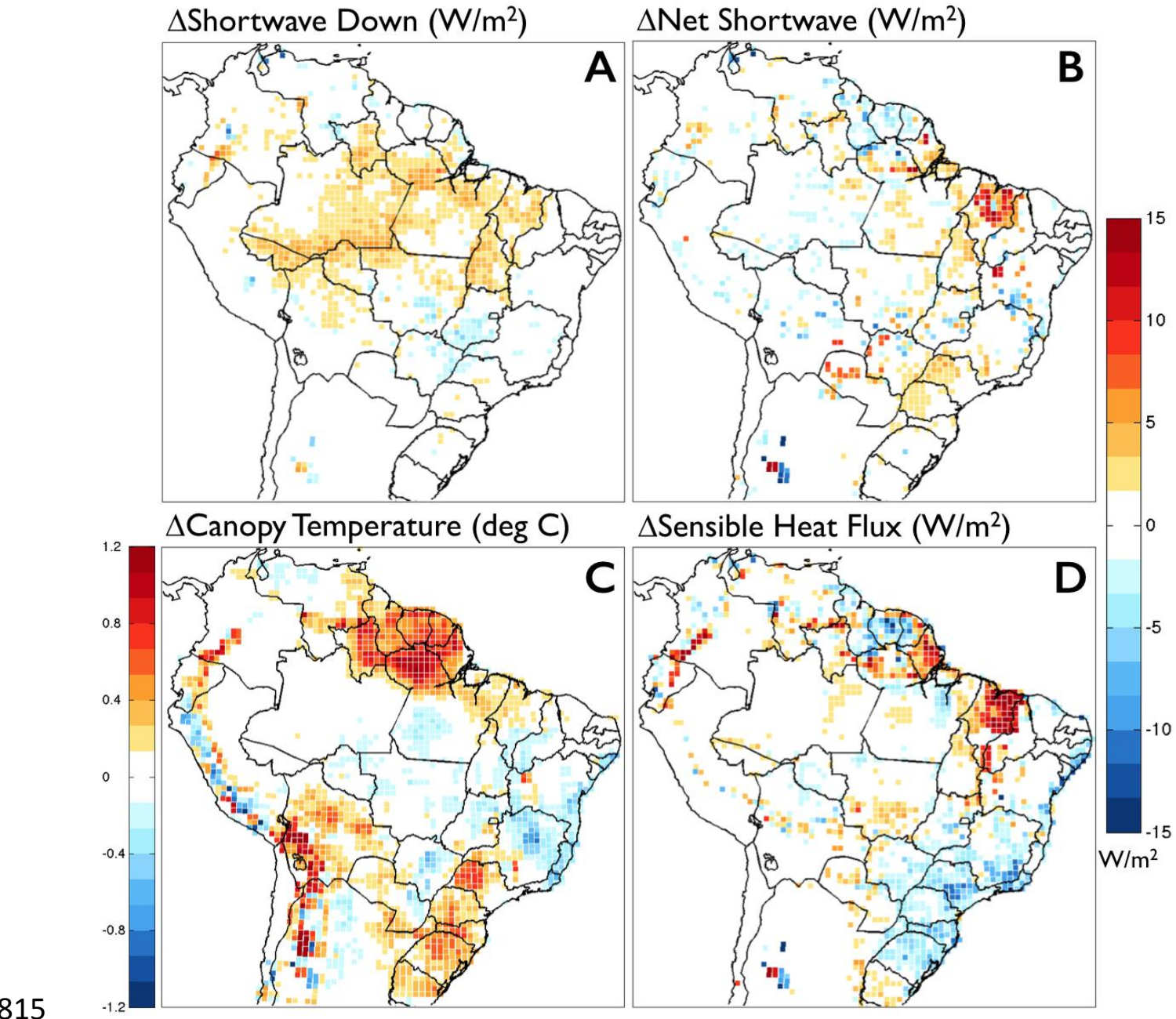

$\Delta$ Net Shortwave $\left(\mathrm{W} / \mathrm{m}^{2}\right)$

Figure 6: $\Delta$ Surface Energy Flux Components $\left(\mathrm{W} \mathrm{m}^{-2}\right)$ and Temperature $(\operatorname{deg} \mathrm{C})$ : The change in annual mean (A) downwelling shortwave at the surface in $\mathrm{W} \mathrm{m}^{-2},(\mathrm{~B})$

818 shortwave radiation absorbed by the surface in $\mathrm{W} \mathrm{m}^{-2},(\mathrm{C})$ canopy temperature in degrees $819 \mathrm{C}$, and (D) sensible heat flux in $\mathrm{W} \mathrm{m}^{-2}$ are shown for the Future Current land use cases. 820 The color bar scale for panels A, B, and D is shown to the right side of the map. The 821 color bar scale for panel $\mathrm{C}$ is shown to the left of the panel. 
$\triangle \mathrm{CAPE}$, Aug \& Sept $(\mathrm{J} / \mathrm{kg})$
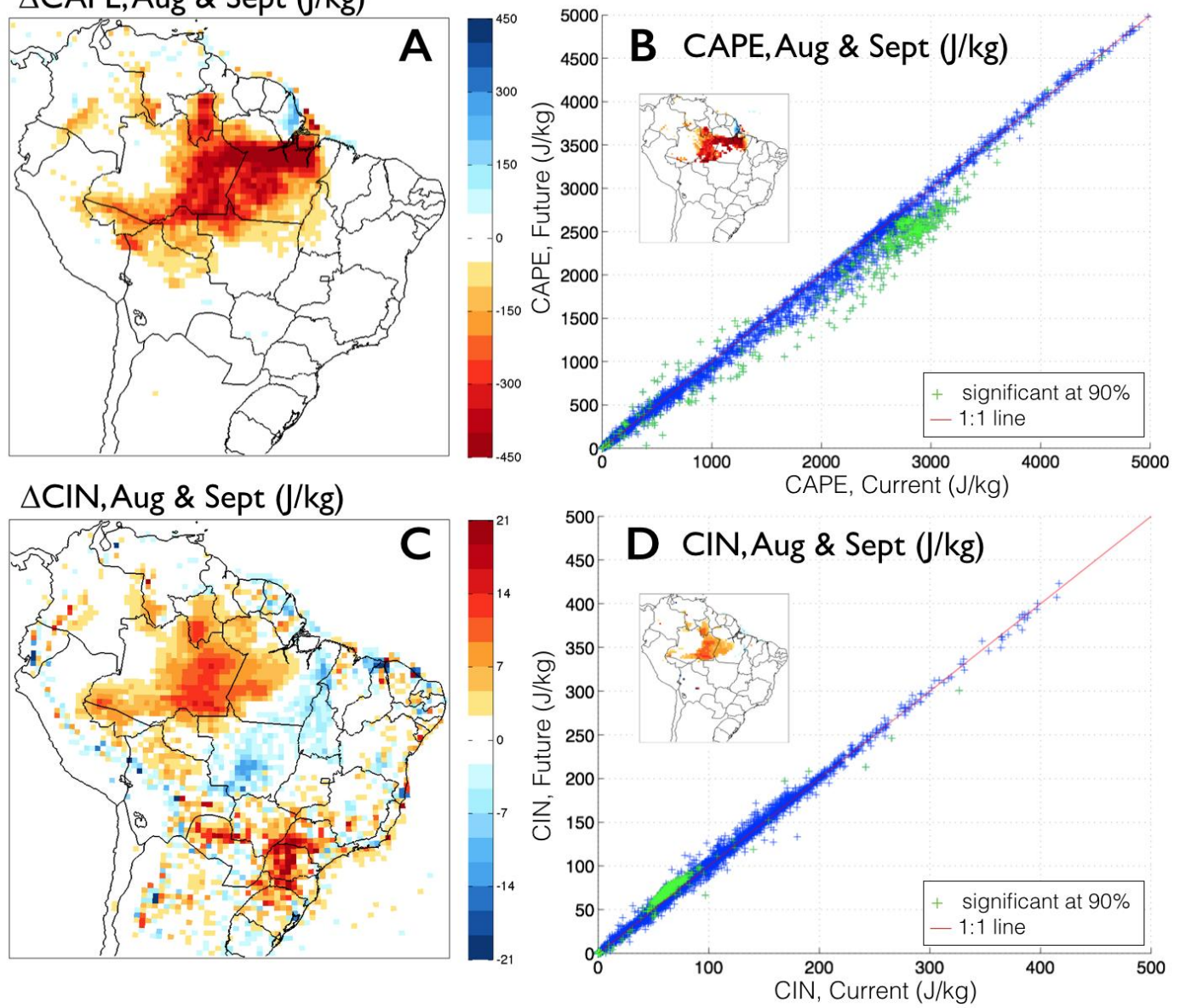

Figure 7: $\triangle \mathrm{CAPE}$ and CINE: The change in August and September mean (A) Convectively Available Potential Energy (CAPE) in $\mathrm{J} \mathrm{kg}^{-1}$ and (C) Convective Inhibition Energy (CIN) in $\mathrm{J} \mathrm{kg}^{-1}$ are shown for the Future - Current land use cases. Red colors indicate a drier atmosphere, and blue colors indicate a wetter atmosphere. The Current vs Future (B) CAPE and (D) CIN are plotted for each gridpoint in blue symbols with changes (Future-Current) that are statistically significant at $90 \%$ confidence plotted in green. Values which fall below the 1:1 line (shown in red) are decreasing in the future, and values which are above the 1:1 line are increasing in the future. Inset maps in panels $\mathrm{B}$ and D show the spatial location of green points which pass the significance test. 
+ deforestation

- leaf area

$\downarrow$

- latent heat flux

+ runoff

- moisture stress
- CAPE

$+\mathrm{CIN}$

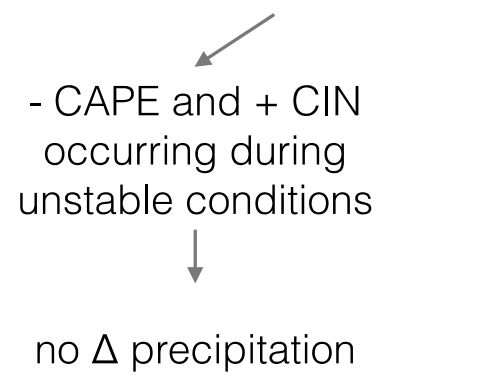

841

842 Figure 8: Schematic showing the hypothesized relationship between deforestation, water 843 cycling, and precipitation found in this study. CAPE is a measure of potential energy 844 available for convection, and CIN is a measure of convective inhibition.

845 